\title{
GUIDELINES TO CREATE A POSITIVE CLASSROOM CLIMATE FOR RELIGION EDUCATION: AN EMPATHETIC APPROACH
}

\author{
Andrew D Abdool \\ Marlize Drinkwater \\ North-West University - Potchefstroom Campus \\ South Africa
}

\begin{abstract}
The situation in the education system in South Africa is not unique when compared to other countries in the world, but the situation has brought about changes and educators have to deal with change, especially in the classroom with multi-cultural learners with different religions. These changes in the constitution of South Africa since 1993 have had many implications for education and the new constitution emphasises the equal treatment of all people, regardless of gender, race or religion. For the teaching of Religion Education an inter-religious dialogue is of the utmost importance and teaching has to be approached empathically. This aspect of classroom climate will be discussed in particular.
\end{abstract}

Key Concepts: Equality, classroom climate, empathetic approaches

\section{Introduction and purpose of the paper}

The teaching of Religion Education in South African schools is not an easy task. In the policy of Religion Education the Minister of Education stresses the point that religion education must extend the concept of equity to the combination of religion and education in a way that celebrates the religious diversity of our country. This document promotes the importance of how schools should contribute to the teaching and learning about religion and religions (National Policy Document, 2003).

With a multicultural school environment there needs to be guidelines to assist the teacher in the classroom with this task. It has to be borne in mind that not all teachers have been equipped with the necessary skills to create a favourable classroom climate and that the classroom is the heart of a school. If teachers as well as learners are not empowered appropriately, it could lead to dysfunctional schools (Monyooe, 1999:70).

Fraser (1998) and Tobin (Fraser \& Tobin, 1998) have proved that classroom climate has a great influence on learning and achievement. According to Zabel and Zabel (1996:270284), Abdool (2000:30-48) and Drinkwater (2002) it is an art to create a positive classroom climate and believe in equipping teachers with appropriate knowledge, skills and a positive attitude that could lead to an environment of good teaching.

Thus, the purpose of this article is to give a holistic or general overview of guidelines to create a positive classroom climate and to propose guidelines for an empathetic approach towards Religion Education in the classroom. 


\section{The Concept Classroom Climate and Types of Climates}

There are different definitions of the concept classroom climate. For the purpose of this article classroom climate will be described as the quality of the atmosphere, tone, ethos or ambience of the class, as influenced primarily not only by the teacher and the learners, but also by the managerial, physical, psychosocial, and teaching-learning aspects of that class.

There are different types of classroom climates and Seiler, Schuelke and Lieb-Brilhart (1984:194-240) give a more detailed explanation of different types of classroom climate and in each instance contrast two types of climate with each other:

\section{- An open versus a defensive climate}

In an open climate learners feel free to communicate with the teacher and ask for help. Teachers respond to their request, give feedback and offer help. In contrast, within a defensive climate, learners are criticised and negative messages are communicated. Learners are not eager to respond and become defensive. In an open climate the teacher make learners feel welcome, pay attention and create a relaxed and pleasant atmosphere.

\section{- A climate of confidence versus fear}

In a climate of confidence, more time is spent on teaching than control and punishment. The teachers as well as the learners feel competent to teach and learn respectively. In contrast, a climate where there is fear results in learners feeling intimidated by the status of the teacher and they are afraid of making mistakes. It is important to listen carefully and give learners undivided attention or they will feel that they are wasting their time. If teachers listen attentively it could build confidence in the relationship between teachers and learners.

\section{- A climate of acceptance versus rejection}

In this type of climate learners feel that they are accepted unconditionally as part of the classroom. They are aware that the teacher accepts them as they are with their abilities, shortcomings and character, whereas with rejection they feel alienated from what is happening in the classroom. An essential characteristic of effective teaching is to be sensitive and responsive to the individual needs of learners. Learners will respect you when they know that they have a voice in not only how they learn, but also in what they learn.

\section{- A climate of belonging versus alienation}

In a climate of belonging, learners feel that they are part of what happens in the classroom whereas in a climate of alienation things happen whether they are present or not.

\section{- A climate of trust versus distrust}

A climate of trust allows learners to communicate their grievances and differences, whereas where distrust reigns, learners will do the opposite.

\section{- A climate high versus low expectancies}

In a climate of high expectancies, teachers expect learners to succeed concerning learning tasks and communicate them, whereas in a climate of low expectancies messages of failure, accusations, attributes of failure, such as low ability and lack of motivation are given to learners. 
- A climate of order versus disorder

In an ordered environment, rules are clear and known to learners. Time is utilised optimally on academic tasks and tasks are mastered efficiently in a climate of order. Where disorder reigns more time has to be spent on controlling behaviour and little teaching and learning takes place.

It is important that the rules referred to may not include personal attacks. Every learner has an opportunity to talk at and every learner has the right to his or her opinion. According to Smith (2001:33) making rules should be a collaborative exercise where every learner is a participant, they have to be involved in order to establish, define and understand the rules.

\section{- A climate of control versus frustration}

In a climate of control teachers as well as learners believe that their acts and behaviour can contribute towards their future success. Where frustration reigns both the teacher and learners believe that success relies on good luck and the input of others - they feel frustrated and feel that their decisions do not carry any weight.

It becomes clear after the different types of classroom climates that have been discussed, that the teacher plays a major role in creating a positive classroom climate that is conducive to learning.

\section{The Concept Multireligion Education}

According to the policy for Religion and Education (2003) South Africa is a multi-religious country which consists of Christians, indigenous African religions, Islam, Judaism, Hinduism, Buddhism, Rastafarianism, Bahai, and other religions. Religion Education must contribute to developing basic skills in observation listening, reading, writing and thinking. The study of Religion Education must not promote one singular religion, but create knowledge of the major religions so that it can increase understanding, build respect for diversity, value spirituality and clarify the religious and non-religious sources of moral values.

Du Toit and Kruger (1998:32-50) define the concept multi-religious education as giving access to and learning more about a diversity of religions - and one framework of understanding: In one syllabus, one handbook, one classroom, by one teacher. It is not intended to destroy or create faith as an opportunity to be given information and knowledge and of becoming a mature human being. According to Kruger, Lubbe and Steyn (2002:22) religion education is the training in religious literacy to know and understand (not practice) more than one religion and could be of personal and cultural enrichment. To summarise the definition for our understanding: Religion education is a subject where the learners of South Africa will have the advantage to broaden their perspective and will be able to have interreligious dialogue and have respect for each other as citizens of this country.

\section{General Guidelines to Create a Positive Classroom Climate for Religion Education}

General guidelines appropriate for creating a suitable climate for Religion Education are hence discussed.

\section{- Guideline 1}

Teachers should be aware of the fact that the learners in one class may find themselves at different stages of intellectual, social, moral and emotional development and that 
opportunities for growth concerning these aspects have to be created. By creating conflict or dissonance (concerning intellectual social moral or emotional matters) in class, opportunities for growth are created (Woolfolk, 1995:81).

\section{- Guideline 2}

Teachers should be aware of and be sensitive towards the differences of learners concerning their learning and communication styles. To be able to accommodate these differences teachers should make use of as many types of teaching models and strategies as possible (Lage, Platt and Treglia, 2000:31).

\section{- Guideline 3}

If the emphasis is only placed on the differences among learners, there will not be a healthy esprit de corps in the classroom, which is imperative for effective learning (Cangelosi, 1993:85). Therefore cooperation and cooperative learning should receive attention.

\section{- Guideline 4}

To acquire a holistic perspective of learners and their behaviour, demands that teachers get to know as much as possible about learners' family, social and cultural and religious backgrounds. Learners from poor socio-economic backgrounds, for example, might lack the means to function properly in a school and this may lead to behaviour that the teacher does not understand or find unacceptable. In South Africa, where learners from different cultures were formerly separated in schools, teachers do not know the cultural and religions expressions and habits of learners from different cultures. They might demean the integrity of these cultures, alienating and disempowering these learners. By acknowledging the legitimacy of their cultural expressions we give the children their own voice in the classroom (Boykin, 1994:250).

\section{- Guideline 5}

Communication (both verbal and non-verbal) has a direct and indirect influence on classroom climate. Teachers should make use of the appropriate communication style components (Ankiewicz, 1990), convey the correct messages with their non-verbal communication, listen with empathy and attempt to prevent and/or surmount communication apprehension. Learners should also be encouraged to voice their opinions in order to improve their communication skills.

\section{- Guideline 6}

Improving the higher-order thinking skills of learners is inevitable for effective teaching. A certain type of classroom climate is demanded for enhancing higher-order thinking skills (Cole, Sugioka, and Yamagata-Lynch, 1999). Such a climate could be described as one in which learners feel secure and where the making of mistakes as well as their own way of thinking about their religion is allowed.

\section{- Guideline 7}

A climate of respect toward each other and the environment (including other's possessions, culture and religion) should be created (Krall and Jalongo, 1998/99:88). According to Kauffman and Burbach (1998:15), ... teachers have to establish themselves as people of integrity who are honest and consistent in their dealings with students. (Emphasis added.) This will lead to learners' trusting the teacher and bonding more closely with him/her, which in turn could lead to moral commitment. 


\section{- Guideline 8}

The climate in the classroom should be one of involvement. Huffman, Lawrenz and Minger (1997:801) say: If students are to truly learn (Religion Education), they need to be actively involved almost all the time - not just sometimes.

These are general didactic guidelines for teachers who wish to create a favourable classroom climate in Religion Education classes. A primary feature of these classes should be the empathy of the teacher and learners towards each other and each other's beliefs. Empathy, a primary didactic guideline, is discussed in the following paragraphs.

\section{Empathy as a Primary Didactic Guideline towards a Positive Climate in the Religion Education Classroom}

Before suggestions are made as to how empathy could be implemented in the Religion Education classroom, the concept empathy will firstly be defined.

Ciaramicoli and Ketcham $(2000: 4,11)$ define empathy as the capacity to understand and respond to the unique experiences of another person and increase the awareness of other people's thoughts and feelings. Bennett (1995:314-315) explains empathy as something more than just knowledge about the following person, but trying to imagine oneself in another's shoes or bare feet. Empathy varies from trying to understand how other people think and view the world to how people emote, feel or sense.

In the work of Egan (2002:48-49) he describes the concept empathy the perspectives of Kohut (1978) which states that empathy is the accepting, confirming and understanding of the human ego evoked by the self; it is a psychological nutrient without which the human life, if we don't cherish it, could not be sustained and Covey (1989) which sees empathy as psychological air that helps people to breathe more freely in their relationships. Goleman $(1995,1998)$ puts empathy at the heart of emotional intelligence and calls it a social radar through which one senses other's feelings and perspectives and takes an active interest in their concern. Bolton (1979) defines empathy as the ability to feel with another person, to walk with another person and see things from their world in a non-judgmental and nonprejudicial way, while maintaining some separateness.

The whole nature of empathy could be seen as a commitment to work at understanding each person (learner) from his or her point of view together with the feelings surrounding it and to understand individuals in and through the context of their lives. It is important to take note that where sympathy seeks to console, empathy works to understand. Being empathetic is much more than having empathy, because it is what we do with empathy that counts. To express empathy is not that simple. Psychologists say that empathy is hard work involved in accurately understanding other people's emotions and then responding in ways that honour the uniqueness of the individual and the situation.

Learning how to express empathy, putting your thoughts and feelings into words that will find your way to another person's heart and soul requires self-awareness, careful reflection and a considerable amount of practice. Here are seven guidelines that could help to express empathy in the Religion Education classroom (Ciaramicoli and Ketcham, 2000:46-63). 


\section{Seven Guidelines to Express Empathy}

\section{- Ask open-ended questions}

Open-ended questions express empathy because they convey respect for the individual's unique reactions and responses. When you ask an open-ended question you communicate the fact that you want to learn from the other person and that you are truly interested in his or her perspective. Close-ended questions slam the door in people's faces, while openended questions reveal the unlimited possibilities that exist when we put our prejudices and preconceptions aside, swinging the doors wide open to new experiences.

- Slow down

Empathy always makes an effort to slow things down so that emotions can be tempered with thoughtful reflection. Emotions that run high are not conducive to expressing empathy. Slowing things down allows thoughts and ideas to catch up with feelings, inserting some calm and reason into an emotional situation.

\section{- Avoid snap judgements}

Quick decisions and snap judgements are not part of empathy's repertoire of expressions. If you have enough knowledge about the other person's thoughts, beliefs, culture, emotions and past history it won't help to make any judgements.

- Pay attention to one's body language

We have to pay attention our facial expressions, vocal inflections, gestures and even our posture. A smile is the most powerful expression of empathy available.

\section{- Learn from the individual's past}

In expressing empathy it is important to relate to a person's past or background. To be fully involved, by knowing more, could help to understand the person better without any prejudice or negative accusations.

\section{- Let the story unfold}

Every person has a unique story to tell. If you just listen to the next person attentively then it could solve some problems. Empathy will help one to take note that this is this person's journey; one just has to let him or her know that one is listening to the story.

\section{- Set limits}

Setting limits is a way of letting empathy do its work and keeping focussed on the issues at hand. These boundaries help us to tolerate our differences.

To summarise the abovementioned: It seems that the important element for expressing empathy is not in the words that we express, but the underlying message that we communicate. Primarily we are immersing ourselves as teachers into another person's world of religion and have the opportunity to experience and reach out and broaden our perspective and expand our connection to life. Empathetic behaviour is in essence an art that is discussed in the following paragraphs. 


\section{The art of Empathetic Behaviour}

Empathy is a true survival skill, an inborn capacity to understand other people's thoughts, ideas, beliefs, feelings and it is a powerful drive that inspires us to create close friendships and caring communities. It takes us deep into the heart to know what it means to be really human. Eight behaviours enhancing empathy that can be classified as spiritual principles such as honesty, humility, acceptance, tolerance, gratitude, faith, hope and forgiveness will be briefly discussed according to Ciaramicoli and Ketcham (2000:155-240).

\section{- Honesty}

Empathy defines honesty as the ability to see oneself clearly, to understand others accurately and to communicate those perceptions in a sensitive and tactful way. Honesty that originates from empathy is always respectful, honouring the individual's unique experiences, but placing great value on the relationship. Empathy, like respect, appreciates differences, but always seeks common ground.

\section{- Humility}

It is the place of balance where one knows who one is and is not. Empathy guides one to a humble position by keeping one focused on the truth of one's behaviour and allowing one to see oneself. It also brings one to a place where one acknowledges one's strengths and weaknesses so that one realises that to be humble one cannot make comparisons and that empathy expands with humility and contracts with arrogance and pride.

\section{- Acceptance}

To define acceptance one has to bear in mind that one has to accept oneself with all one's contradictions and complications. One must also accept the inevitable contradictions and complications that arise in every human relationship when two contradictory, complicated people meet each other. Empathy leads one to acceptance by enlarging one's perspective. One sees oneself in a bigger picture, how one fits in a relationship with others, finding one's place in the larger community and one learns that one can only accept oneself if one accepts the need for one another.

\section{- Tolerance}

Tolerance can be defined as the willingness to put up with differences. As empathy expands our consciousness throughout our lives, it creates an active appreciation and abiding respect for the great diversity of life in this world. Tolerance goes deep: Looking beyond the colour of people's skin, beliefs, religion (or church they attend), the neighbourhood where they live, the careers they pursue, through this we discover common ground. It also helps us to build bridges to others whom we dislike. Empathy allows us to see through their eyes, borrow their skin, enter their world of faith or religion and you totally enter into the next person's world. To be tolerant you need also to be patient.

\section{- Gratitude}

Gratitude in empathy's dictionary is not just a feeling, but also a way of experiencing and interacting with the world. It is a response that links one person to another and a realisation that people are dependent on each other. It leads one to the giftedness of life and to appreciate it - irrespective who one is. 


\section{- Faith}

Faith gives confidence. Empathy leads one through one's doubts to discover faith and it can change a person's immediate experience of the world by altering one's experience and directly affect the way people understand and interact with each other. To have faith in each other builds a relationship that will treat the other with respect.

\section{- Hope}

Hope that is inspired by empathy is not a belief that everything will turn out all right; rather it is a conviction that even if things do not work out we will find a way. Hope is conveyed in both one's attitudes and actions. Hope is not a passive state of waiting for something good to happen, but an active pursuit of goodness. To discover hope is to have willingness to change. When one is inflexible, rigid, unbending, and unyielding one creates a thick wall that hope cannot penetrate. But when one bends, is flexible, yields and surrenders, then hope finds its wings.

\section{- Forgiveness}

If one cannot forgive oneself it is impossible to forgive others. It comes with experience and it takes time and effort, but one moves forward, building on the past rather than repeating it endlessly. Forgiveness is not something that one commands and controls but an experience that arises from hard work of empathy. Seeking to understand, opening one's mind [and our own heart] to what was once hidden from view, one sees what one could not see before, and in that widened perspective forgiveness comes to one unexpectedly, like a sudden bend in the trail that opens up to reveal a view of the world one has never seen before.

To understand forgiveness, one has to acknowledge that one did something wrong, apologise to the person that you have harmed, compensate that person if possible and try not to repeat the mistake. South African Archbishop Desmond Tutu said that forgiveness is the absolute necessity for continued human existence. Forgiveness unlocks the door to set someone free and realising that one too was a prisoner all along.

\section{Conclusion}

To conclude this article we think it is important for educators in our country, South Africa, to make a paradigm shift concerning important issues in the classroom of the $21^{\text {st }}$ century. These proposed guidelines to create a positive classroom climate in the Religion Education class with an empathetic approach will reduce the fear of both teachers and learners and a positive message will reach the parent community, as they may also have fears in this regard. 


\section{BIBLIOGRAPHY}

Abdool, AD 2000. Didaktiese riglyne vir die skep van 'n positiewe klasklimaat aan 'n sekondêre skool. Potchefstroom: PU for CHE. (MEd-dissertation).

Ankiewiczs, PJ 1990. Die invloed van opleiding op die kommunikasiestyl van Natuur-en Skeikunde-onderwysstudente. Potchefstroom: PU for CHE. (PhD-Thesis).

Bennett, CI 1995. Comprehensive Multi cultural Education. Theory and Practice. $3^{\text {rd }}$ ed. Boston: Allyn and Bacon.

Bolton, R 1979. People skills: How to assert yourself, listen to others and resolve conflict. Englewood Cliffs/New Jersey: Prentice Hall.

Boykin, AW 1994. Afrocultural expression and its implications for schooling. Teaching diverse populations. Formulation a knowledge base, eds. Hollins, ER; King, J \& Hayman, W. Albany: State University of New York Press. 243-256.

Cangelosi, JS 1993. Classroom management strategies. Gaining and maintaining students' cooperation. New York: Longman.

Ciaramicolli, A and Ketcham, K 2000. The power of empathy. A practical guide to creating intimacy, self-understanding and lasting love. New York: Dutton.

Cole, DG, Sugioka, HL and Yamagata-Lynch, LC 1999. Supportive classroom environments for creativity in higher education. Journal of creative behaviour. 33(4):277-293.

Drinkwater, M 2002. Didactical guidelines for creating a favourable classroom climate in outcomes-based physical science classroom. Potchefstroom: Potchefstroom University for Christian Higher Education. (PhD-Thesis).

Du Toit, CW and Kruger, JS 1998. Multi-religious Education in South Africa. Problems and prospects in a pluralistic society. Pretoria: University of South Africa.

Egan, G 2002. The skilled helper: A Problem-Management and Opportunity-Development Approach to helping. $7^{\text {th }}$ ed. Pacific Grove: Brooks/Cole Thomson Learning.

Fraser, BJ 1998. Science learning environments: assessment, effects and determinants, International handbook of science education, eds. Fraser, BJ \& Tobin, KG. Boston: Kluwer Academic.

Fraser, BJ and Tobin, K 1998. Student perceptions of psychosocial environment in classrooms of exemplary science teachers. International journal of science education. 11:19-34.

Huffman, D, Lawrenz, F and Minger, M 1997. Within-class analysis of ninth-grade science students' perceptions of the learning environment. Journal of research in science teaching. 34(8):791-804.

Kaufmann, JM and Burbach, HJ 1998. Creating classroom civility. Education digest. 63(1):12-18.

Krall, CM and Jalongo, MR 1998/1999. Creating a caring community in classrooms. Childhood education. 2:83-89, Winter.

Kruger, JS, Lubbe, GJA and Steyn, HC 2002. The Human Search for meaning - A multireligious introduction to the religions of humankind. Pretoria: Via Afrika.

Lage, MJ, Platt, GJ and Treglia, M 2000. Inverting the classroom: a gateway to creating an inclusive learning environment. Journal of economic education. 31(1):30-43, Winter. 
Monyooe, LA 1999. Creating favourable conditions for the culture of learning and teaching in South Africa: some reflections. South African journal of higher education. 13(3):69-79.

Seiler, WJ, Schuelke, LD and Lieb-Brilhart, B 1984. Communication for contemporary classroom. London: Holt, Reinhart \& Winston.

Smith, SW 2001. Strategies for building a positive classroom environment by preventing behaviour problems. Intervention in School and Clinic. 37(1):31-35, September.

Woolfolk, AE 1995. Educational Psychology. Boston: Allyn and Bacon.

Zabel, RH and Zabel, MK 1996. Classroom management in context. Boston: Houghton Mifflin Co.

\section{Reports}

2003 National Policy on Religion and Education. Department of Education, Pretoria: Governmental Printers. 


\section{CONTRIBUTORS}

DR ROBERT JACKSON is professor of Education and Director, WRERU, Institute of Education, University of Warwick.

Contact details: r.jackson@warwick.ac.uk

DR GEIR SKEIE is an Associate Professor at the Faculty of Humanities, Stavanger University College, Norway. He teaches Religious Studies and Religious Education. Contact details: geir.skeie@ hum.his.no

DR WOLFRAM WEISSE is Professor in Religious Education and Ecumenical Theology, University of Hamburg.

Contact details: weisse@erzicip.erwiss.uni-hamburg.de

DR CORNELIA RouX is an Associate Professor in Curriculum Studies (Religion Studies Inclusivity and Diversity in Religions, Belief systems and Cultures), Faculty of Education, Stellenbosch University.

Contact details: cdr@sun.ac.za

Petro du PREEZ is a Masters student in Curriculum Studies, Faculty of Education, Stellenbosch University. Her interests are in Human Rights, Values and Religion.

Contact details: relignav@ sun.ac.za

DR INA TER AVEST is a lecturer in Religious Education at CHN University at Leeuwarden and senior researcher at the Free University of Amsterdam.

Contact details: iteravest@chn.nl

DR COK BAKKER is a Professor in Religious Education at Utrecht University.

Contact details: cbakker@theo.uu.nl

CHRISTINE MÜLLER is currently writing her doctoral thesis about the relevance of religion for Jewish pupils in Germany. She is a student at the University of Hamburg.

Contact details: christine@mueller-mail.com

DR URSULA GÜNTHER is at the University of Hamburg.

Contact details: guenther_ursula@erwiss.uni-hamburg.de 
ELISABETH ARWECK is a Research Fellow at the Warwick Religions and Education Research Unit (WRERU), Institute of Education, University of Warwick.

Contact details: e-mail: elisabeth.arweck@warwick.ac.uk

DR ELEANOR NESBITT is a Reader, WRERU, Institute of Education, University of Warwick.

Contact details: eleanor.nesbitt@warwick.ac.uk

DR GORDON MITCHELL is a Professor for Religion and Intercultural Education at the University of Hamburg.

Contact details: mitchell@erwiss.uni-hamburg.de

DR ANDREW ABDOOL is a lecturer in Religion Studies, Biblical Studies Didactics and the Philosophy of Education at the School of Education and Training, Faculty of Education, North-West University.

Contact details: sooada@puk.ac.za

DR MARLIZE DRINKWATER is a lecturer at the School of Education and Training, Faculty of Education, North-West University, Potchefstroom Campus.

Contact details: soomd@puk.ac.za 